\title{
Epidemiological aspects of rheumatoid arthritis patients affected by oral bisphosphonate-related osteonecrosis of the jaws
}

\author{
Nicolau Conte-Neto ${ }^{*}$, Alliny Souza Bastos ${ }^{\dagger}$, Rosemary Adriana Chierici Marcantonio ${ }^{\dagger}$ and \\ Elcio Marcantonio Junior ${ }^{\dagger}$
}

\begin{abstract}
This literature review aims to evaluate the epidemiologic profile of patients with rheumatoid arthritis (RA) that developed a bisphosphonate-related osteonecrosis that affect the jaws (BRONJ), including demographic aspects, as well as clinical and therapeutic issues. A search of PUBMED/MEDLINE, Scopus, and Cochrane databases from January 2003 to September 2011 was conducted with the objective of identifying publications that contained case reports regarding oral BRONJ in RA patients. Patients with RA who develop oral BRONJ are usually women above 60 years taking steroids and long-term alendronate. Most of them have osteoporosis, and lesions, triggered by dental procedures, are usually detected at stage II in the mandible. Although there is no accepted treatment protocol, these patients seem to have better outcomes with conservative approaches that include antibiotic therapy, chlorhexidine, and drug discontinuation.
\end{abstract}

Keywords: Rheumatoid arthritis, Bisphosphonate, Jaws, Osteonecrosis

\section{Background}

Bisphosphonates (BPs) are stable synthetic analogs of inorganic pyrophosphate that suppress osteoclastmediated bone resorption [1]. In this way, they have been widely used to stabilize bone loss in patients with rheumatoid arthritis (RA), especially those who develop osteoporosis, which is a common feature in this rheumatic disease [2]. However, since 2003, great concern has been generated regarding the side-effects of these drugs through increasing reports, worldwide, of a bisphosphonate-related osteonecrosis that affect the jaws (BRONJ).

There are many hypotheses regarding BRONJ pathogenesis, but none of them is completely accepted. Although there have been reports with no obvious co-morbidity factors $[3,4]$, it is reasonable to believe that co-factors may play a relevant role in the development of these lesions, especially in patients taking oral BPs. Among these cofactors, RA has been included as a relevant risk factor for

\footnotetext{
* Correspondence: conteneto@hotmail.com

† Contributed equally

UNESP- Univ. Estadual Paulista, School of Dentistry, Department of Diagnosis and Surgery, Division of Periodontology, Rua Humaitá, 1680, 14801-903 Araraquara, SP, Brazil
}

(c) 2012 Neto et al; licensee BioMed Central Ltd. This is an Open Access article distributed under the terms of the Creative Commons Attribution License (http://creativecommons.org/licenses/by/2.0), which permits unrestricted use, distribution, and reproduction in any medium, provided the original work is properly cited.

BRONJ; however, until now the relationship between these diseases has not been fully explained.

Due to the greater number of patients taking oral BPs for the treatment of RA and osteoporosis, it is very important for risks to be assessed. Thus, the purpose of this extended literature review is to evaluate relevant issues of patients with RA who developed oral BRONJ, including demographic, clinical, and treatment aspects, with the goal of establishing comparative associations with patients without RA who developed oral BRONJ.

\section{Methods}

We performed a computerized search to identify all papers published in English from January 2003 to September 2011 in PUBMED/MEDLINE, Scopus, and Cochrane databases. Case reports, case series, and retrospective studies were included, while short communications and letters to the Editor were excluded. The studies were approved by the Ethics in Human Research Committee and were in compliance with the ethical principles of the Helsinki Declaration. Literature reviews and systematic reviews also were considered with the objective of identifying cases already reported. The key MeSH (Medical Subject 
Headings) terms used were: diphosphonates, bisphosphonate, jaw osteonecrosis, rheumatoid arthritis, and rheumatologic.

The primary objective was to identify all articles containing clinical reports with the following inclusion criteria:

- Diagnosis of RA and oral BRONJ

- Patients with no prior history of radiation to the craniofacial region

- Non-neoplasic patients

- At least five areas of the specific demographics were collected, including gender, age, bisphosphonate type and length of exposure, concomitant medications, trigger event, clinical features, staging, lesion site, imaging and histological features, as well as management and outcomes. The stage of the lesions was retrieved directly from the papers or it was defined based on the available clinical data and according to the classification system by Ruggiero et al. [5].

- Papers published in English

All titles and abstracts from the results of the literature search were reviewed by the authors for potential inclusion in our study. We also searched the related links of all relevant papers. Furthermore, all relevant papers were checked to avoid multiple inclusions of the same patients in this study.

\section{Results}

The search strategy yielded 1606 titles/abstracts from the databases analyzed. After title, abstract screening, and/or paper analyses, 331 potentially relevant studies were identified and screened for retrieval. Of these, 312 studies were excluded due to non-compliance with the inclusion criteria, one paper was excluded due to duplicity of one patient and, finally, 17 were included in the present review, consisting of 27 patients and 29 BRONJ lesions (Tables 1, 2, 3, and 4).

\section{Patient characteristics}

The patients from this literature review ranged in age from 55 to 79 yr and the mean age was 67 years. Among the 22 patients whose age was reported, 17 (77.3\%) were above 60 years old [6,8,10-12,14-16,18-21], 25 patients reported the gender and only one was male [12] (Table 1). Furthermore, osteoporosis was the most common co-morbidity observed in this review, being present in 18 patients (66.6\%) [4,9-11,14-16,18-21], followed by hypertension (29.6\%) $[6,16,18-20]$ and diabetes mellitus $(14.8 \%)[8,15,20]$ (Table 1$)$.

\section{Characteristics of bisphosphonate treatment}

Among the 24 patients that reported the use of BPs, 22 $(91.6 \%)$ affirmed to use alendronate $[4,6-9,11,12,15$, $16,18-21]$, while 2 other patients were using ibandronate
[14] or risedronate [10] (Table 1). The mean duration of $\mathrm{BP}$ therapy was 48 months, ranging from 6 months to 10 years, and most of the patients (73\%) were using BPs for 3 or more years $[4,6,9,12,15-17,19-21]$ (Table 1).

\section{BRONJ characteristics}

Most of the oral BRONJ cases in this literature review were triggered by dental surgery procedures (51.7\%), such as tooth extraction and dental implants, observed in 13 patients $[4,5,7-9,12,14,17-20]$. Of note, a large proportion of BRONJ lesions appeared spontaneously (41.38\%) [9,10,12,13,15,19-21] (Table 2).

BRONJ lesions were located most commonly in the lower jaw $(72.4 \%)$, especially in the posterior area $[4,6,9,12-15,17,19,21]$. The main signs and symptoms reported in the studies included: bone exposure in $82 \%$ of the lesions $[4,6,7,9,11-18,20,21]$, followed by pain $(78.5 \%)$ [4,6,7,10-14,16-21], edema (35.7\%) [6,7,10,12,15,17-19,21] and purulent discharge (35.7\%) [6,11,13-15,17,19,21]. Moreover, according to a staging system [9], 28 lesions were diagnosed at stage II or III, and only one was at stage I (Table 2). Furthermore, most of the patients (62.5\%) presented a lytic pattern observed on image exams $[4,12$, 16-19,21], followed by bone sclerosis that was reported in six patients $(37.5 \%)[7,12,17,19,21]$.

Regarding the management of the BRONJ lesions, the studies showed the treatment either by conservative therapy alone $(48 \%)[9,10,12,14,17,19,20]$ or associated with surgical procedures (52\%) [4,6,7,12,13,15-19,21]. The treatment only with conservative therapy was associated with the most positive outcomes, including the complete healing of the lesions $(33.3 \%)$ [9,12], partial and general positive results (58.3\%) [10,14,19,20] and only one patient presented a non-healed lesion $(8.33 \%)$ [17] (Table 4).

The association of conservative and surgical therapy showed more diverse results, with complete healing in 3 lesions (25\%) [13,21], partial and general positive results $(41.6 \%)[6,7,12,18,19]$ and 4 lesions were classified as non-healed (33.4\%) [4,6,15,17] (Table 4).

\section{Discussion}

Until the present moment, there is no randomized, controlled, prospective clinical trial that assessed jaw osteonecrosis (ONJ) risk in patients with rheumatoid arthritis who were using oral BPs. In the absence of this data, the present paper performed a critical literature review to investigate the current status of the epidemiological aspects of patients with rheumatoid arthritis affected by BRONJ.

Considering the prevalence of BRONJ lesions in patients with RA, we considered only the raw number of oral BRONJ reports in RA patients, since the accurate number of non-neoplasic patients treated with oral BPs 
Table 1 Patients and Bisphosphonate Therapy Characteristics

\begin{tabular}{|c|c|c|c|c|}
\hline Authors/Study & Gender & Age & Comorbidities & Medications (Years) \\
\hline Marunick et al. [4] CS Patient 1 & $\mathrm{~F}$ & 59 & OST & STE + METX + AL (3) \\
\hline \multicolumn{5}{|l|}{ Yarom et al. [6] RS } \\
\hline Patient 2 & $\mathrm{~F}$ & 73 & HTN & STE + METX + AL (7), infliximab \\
\hline Patient 3 & $\mathrm{~F}$ & 76 & HTN + Arrhythmia + hypercholesterolemia & AL (1.5) \\
\hline Malden \& Pai [7] CS Patient 4 & $\mathrm{~F}$ & 56 & NO & STE + AL (1), leflunomide \\
\hline Khamaisi et al. [8] RS Patient 5 & $\mathrm{~F}$ & 73 & $\mathrm{DM}$ & $\mathrm{AL}(>0,5)$ \\
\hline \multicolumn{5}{|l|}{ Marx et al. [9] CS } \\
\hline Patient6 & $\mathrm{F}$ & NA & OST & $\mathrm{STE}+\mathrm{METX}+\mathrm{AL}(3.1)$ \\
\hline Patient 7 & $\mathrm{~F}$ & NA & OST & $\mathrm{STE}+\mathrm{METX}+\mathrm{AL}(6.3)$ \\
\hline Patient 8 & $\mathrm{~F}$ & NA & OST & $\mathrm{STE}+\mathrm{METX}+\mathrm{AL}$ (3.3) \\
\hline \multicolumn{5}{|l|}{ Hamada [10] CR } \\
\hline Patient 9 & $\mathrm{~F}$ & 68 & OST & STE + RISE (4) \\
\hline \multicolumn{5}{|l|}{ Barrow [11] CR } \\
\hline Patient 10 & $\mathrm{~F}$ & 70 & OST & $\mathrm{STE}+\mathrm{AL}(<3)$ \\
\hline \multicolumn{5}{|l|}{ Junquera et al. [12] CS } \\
\hline Patient $12 a / 12 b$ & M & 73 & NO & STE + METX + AL (3.8) \\
\hline \multicolumn{5}{|l|}{ Mehanna et al. [13] CR } \\
\hline Patient 13 & $\mathrm{~F}$ & 55 & NO & STE + Leflunomide + oral BPs (1) \\
\hline \multicolumn{5}{|l|}{ Favia et al. [14] CS } \\
\hline Patient $14 a / 14 b$ & $\mathrm{~F}$ & 67 & OST & $\mathrm{STE}+\mathrm{IBAN}(1)$ \\
\hline \multicolumn{5}{|l|}{ Kwon et al. [15] CR } \\
\hline Patient 15 & $\mathrm{~F}$ & 71 & OST + DM & $\mathrm{STE}+\mathrm{AL}(3) ; \mathrm{OH}$ \\
\hline \multicolumn{5}{|l|}{$\begin{array}{l}\text { Sedghizadeh et al. [16] RS } \\
\text { no }\end{array}$} \\
\hline Patient 16 & $\mathrm{~F}$ & 63 & $\mathrm{OST}+\mathrm{HTN}$ & STE + chemotherapy + AL (3) \\
\hline \multicolumn{5}{|l|}{ Lo et al. [17] RS } \\
\hline Patient 17 & NA & NA & $\mathrm{NO}$ & oral BPs (4.8) \\
\hline Patient 18 & NA & NA & Hip Osteonecrosis & STE + oral BPs (2.6) \\
\hline \multicolumn{5}{|l|}{ Shin et al. [18] CR } \\
\hline Patient 19 & $\mathrm{~F}$ & 67 & $\mathrm{OST}+\mathrm{HTN}$ & AL (1) + HTN Drug \\
\hline \multicolumn{5}{|l|}{ Park et al. [19] CS } \\
\hline Patient 20 & $\mathrm{~F}$ & 68 & OST & $\mathrm{STE}+\mathrm{AL}(5)$ \\
\hline Patient 21 & $\mathrm{~F}$ & 69 & $\mathrm{OST}+\mathrm{PLE}+\mathrm{TB}$ & $\mathrm{STE}+\mathrm{AL}(10)$ \\
\hline Patient 22 & $\mathrm{~F}$ & 70 & OST + HTN & $\mathrm{STE}+\mathrm{AL}(6)$ \\
\hline \multicolumn{5}{|l|}{ Manfredi et al. [20] CS } \\
\hline Patient 23 & $\mathrm{~F}$ & 68 & $\mathrm{OST}+\mathrm{DM}+\mathrm{HTN}$ & $A L(4.25)$ \\
\hline Patient 24 & $\mathrm{~F}$ & 65 & OST + HTN & $\mathrm{AL}(5)$ \\
\hline Patient 25 & $\mathrm{~F}$ & 79 & OST & $\mathrm{AL}(4)$ \\
\hline Patient 26 & $\mathrm{~F}$ & 57 & $\mathrm{OST}+\mathrm{DM}+\mathrm{HTN}$ & $\mathrm{AL}(>3)$ \\
\hline \multicolumn{5}{|l|}{ Conte-Neto et al. [21] CR } \\
\hline Patient 27 & $\mathrm{~F}$ & 58 & NO & AL (5) \\
\hline Patient 28 & $\mathrm{~F}$ & 68 & OST & $\mathrm{STE}+\mathrm{METX}+\mathrm{AL}(7)$ \\
\hline
\end{tabular}

CS Case series, RS Retrospective study, CR Case report, NA Not available

OST Osteoporosis, HTN Hypertension, DM, Diabetes Mellitus, GU gastric ulcer, PLE Pleuritis, TB Tuberculosis, STE Steroids, MTX Methotrexate; AL Alendronate, RISE Risedronate, IBAN Ibandronate, $\mathrm{OH}$ oral hypoglycemiant

is unknown; therefore, the determination of the precise prevalence of BRONJ is extremely difficult but is possible to be estimated based on epidemiological studies.

Two reviews published recently, reporting patients that presented BRONJ induced by the use of oral BPs, observed a very low prevalence of these lesions in patients with rheumatic diseases [22,23]. Other studies reported that the BRONJ prevalence in patients treated with oral BPs, ranges from $0.001 \%$ to $0.4 \%$ [17,24-27]. These numbers give the idea that the prevalence of 
Table 2 Clinical features of BRONJ lesions in patients with RA

\begin{tabular}{|c|c|c|c|c|}
\hline Authors & Trigger event & Clinical features & Stage & Site \\
\hline \multicolumn{5}{|c|}{ Marunick et al [4] } \\
\hline Patient 1 & Extraction & $\mathrm{BE}+$ pain + seqüestration & $\|$ & Md posterior lingual \\
\hline \multicolumn{5}{|c|}{ Yarom et al [6] } \\
\hline Patient 2 & Implants & $\mathrm{BE}+$ pain + edema + PD + fistula + pathological fracture & III & Md posterior \\
\hline Patient 3 & Extraction & $\mathrm{BE}+\mathrm{NHS}+$ pain + edema + PD + fistula & III & Md posterior \\
\hline \multicolumn{5}{|c|}{ Malden \& Pai [7] } \\
\hline Patient 4 & Extraction & $\mathrm{BE}+$ pain + NHS + edema & III & Mx posterior \\
\hline \multicolumn{5}{|c|}{ Khamaisi et al [8] } \\
\hline Patient 5 & Dental surgery & NA & $\|$ & Md \\
\hline \multicolumn{5}{|c|}{ Marx et al [9] } \\
\hline Patient 6 & Spontaneous & $\mathrm{BE}$ & । & Md lingual \\
\hline Patient 7 & Palatal CT graft & $\mathrm{BE}+$ erythema & $\|$ & Mx posterior palate \\
\hline Patient 8 & Spontaneous & BE & $\|$ & Md posterior lingual \\
\hline \multicolumn{5}{|l|}{ Hamada [10] } \\
\hline Patient 9 & Spontaneous & Pain + edema + sequestration & ॥ & Md \\
\hline \multicolumn{5}{|l|}{ Barrow [11] } \\
\hline Patient 10 & Denture trauma & $\mathrm{BE}+$ pain + PD + erythema & $\|$ & Mx palatine \\
\hline \multicolumn{5}{|c|}{ Junquera et al [12] } \\
\hline Patient $12 a$ & Extraction & $\mathrm{BE}+\mathrm{NHS}+$ pain + hypoesthesia + erythema & $\|$ & Md anterior \\
\hline Patient $12 b$ & Spontaneous & BE + edema + trismus + pain + swelling & $\|$ & Md posterior lingual \\
\hline \multicolumn{5}{|c|}{ Mehanna et al. [13] } \\
\hline Patient 13 & Spontaneous & $\mathrm{BE}+\mathrm{PD}+$ trismus + abscess + pain & $\|$ & Md posterior \\
\hline \multicolumn{5}{|c|}{ Favia et al. [14] } \\
\hline Patient $14 a$ & Extraction & $B E+$ pain + PD & III & Mx posterior \\
\hline Patient $14 b$ & Extraction & $\mathrm{BE}+$ pain + $\mathrm{PD}$ & III & Md posterior \\
\hline \multicolumn{5}{|c|}{ Kwon et al. [15] } \\
\hline Patient 15 & Spontaneous & $\mathrm{BE}+\mathrm{PD}+$ edema & $\|$ & Mx and Md posterior \\
\hline \multicolumn{5}{|c|}{ Sedghizadeh et al [16] } \\
\hline Patient 16 & Denture trauma & $\mathrm{BE}+$ pain + infection & $\|/\| \|$ & Mx \\
\hline \multicolumn{5}{|l|}{ Lo et al [17] } \\
\hline Patient 17 & Extraction & $\mathrm{BE}+\mathrm{PD}$ edema & $\|$ & Md posterior lingual \\
\hline Patient 18 & Extraction & $\mathrm{BE}+$ pain + erythema & $\|$ & Mx posterior \\
\hline \multicolumn{5}{|c|}{ Shin et al. [18] } \\
\hline Patient 19 & Implants & $\mathrm{BE}+$ pain + erythema + edema + increased probing depth & $\|$ & Mx posterior \\
\hline \multicolumn{5}{|c|}{ Park et al [19] } \\
\hline Patient 20 & Implants & Pain + gingival bleeding + PI Pain & $\|$ & Md posterior \\
\hline Patient 21 & Extraction & $+\mathrm{PD}+$ periodontitis & $\|$ & Mx posterior \\
\hline Patient 22 & Spontaneous & Pain + itching sensation + edema & III & Md posterior and anterior \\
\hline \multicolumn{5}{|c|}{ Manfredi et al. [20] } \\
\hline Patient 23 & Spontaneous & $\mathrm{BE}+$ pain + infection & III & Md \\
\hline Patient 24 & Spontaneous & $\mathrm{BE}+$ pain + infection & $\|$ & Md \\
\hline Patient 25 & Spontaneous & $\mathrm{BE}+$ pain + infection & $\|$ & Md \\
\hline Patient 26 & Extraction & $\mathrm{BE}+$ pain + infection & $\|$ & Md \\
\hline \multicolumn{5}{|c|}{ Conte-Neto et al. [21] } \\
\hline Patient 27 & Spontaneous & Pain + infection + increased probing depth + erythema & $\|$ & Md posterior \\
\hline Patient 28 & Spontaneous & $\mathrm{BE}+$ pain + infection + edema + erythema + increased probing depth $+\mathrm{PD}$ & $\|$ & Md posterior \\
\hline
\end{tabular}

$B E$ Bone exposure, $P D$ purulent discharge, NHS non-healing socket, $C T$ connective tissue, $P I$ periimplantitis, $M d$ mandible, $M x$ maxillae 
Table 3 Radiographic and Histologic Features of BRONJ Lesions in Patients with RA

\begin{tabular}{|c|c|c|}
\hline Authors & Radiographic features & Histologic features \\
\hline \multicolumn{3}{|c|}{ Marunick et al. [4] } \\
\hline Patient 1 & Osteolysis + sequestration & $\begin{aligned} \text { Dense nonvital bone } & + \text { subacutely inflamed granulation tissue } \\
& + \text { bacterial colonies }\end{aligned}$ \\
\hline \multicolumn{3}{|c|}{ Yarom et al. [6] } \\
\hline Patient 2 & ID & $\begin{array}{c}\text { CLP inflammatory infiltrate }+ \text { increased vascularity }+ \text { necrotic } \\
\text { bone }+ \text { bacterial colonies }(S \text {. milleri) }\end{array}$ \\
\hline Patient 3 & ID & $\begin{array}{c}\text { CLP inflammatory infiltrate }+ \text { increased vascularity }+ \text { necrotic } \\
\text { bone }+ \text { bacterial colonies (S. viridans) }\end{array}$ \\
\hline \multicolumn{3}{|c|}{ Malden \& Pai [7] } \\
\hline Patient 4 & $\begin{array}{l}\text { Thickening of the left sinus floor and bone density alteration } \\
\text { (suggestion of a retained root in the upper left second PM) }\end{array}$ & Sclerotic and necrotic bone \\
\hline \multicolumn{3}{|c|}{ Khamaisi et al. [8] } \\
\hline Patient 5 & NA & NA \\
\hline \multicolumn{3}{|c|}{ Marx et al. [9] } \\
\hline Patient 6 & NA & NA \\
\hline Patient 7 & NA & NA \\
\hline Patient 8 & NA & NA \\
\hline \multicolumn{3}{|l|}{ Hamada [10] } \\
\hline Patient 9 & NA & NA \\
\hline \multicolumn{3}{|l|}{ Barrow [11] } \\
\hline Patient 10 & Widening of the PLS & NA \\
\hline
\end{tabular}

\begin{tabular}{|c|c|c|}
\hline \multicolumn{3}{|l|}{$\begin{array}{c}\text { Junquera et al. } \\
\text { [12] }\end{array}$} \\
\hline Patient $12 a$ & $\begin{array}{l}\text { Generalized lytic pattern of bone destruction with } \\
\text { superimposed sclerosis of the mandibular ramus }\end{array}$ & $\begin{array}{c}\text { Necrotic osteitis + mixed infiltrate of lymphocytes and } \\
\text { granulocytes }+ \text { medular fibrosis }+ \text { numerous Actinomyces } \\
\text { colonies }\end{array}$ \\
\hline
\end{tabular}

\begin{tabular}{|c|c|c|}
\hline \multicolumn{3}{|l|}{$\begin{array}{l}\text { Mehanna et al. } \\
\text { [13] }\end{array}$} \\
\hline Patient 13 & Marked right neck collection with free gas and midline shift & Normal skin flora with scanty diphtheroids \\
\hline \multicolumn{3}{|l|}{ Favia et al. [14] } \\
\hline Patient $14 a$ & $\mathrm{ID}$ & NA \\
\hline Patient $14 b$ & ID & NA \\
\hline \multicolumn{3}{|c|}{ Kwon et al. [15] } \\
\hline Patient 15 & Osteomyelitis characteristics & NA \\
\hline \multicolumn{3}{|c|}{$\begin{array}{l}\text { Sedghizadeh et al. } \\
{[16]}\end{array}$} \\
\hline Patient 16 & III-defined lytic lesion & NA \\
\hline \multicolumn{3}{|l|}{ Lo et al. [17] } \\
\hline Patient 17 & $\begin{array}{c}\text { Sequestration osteosclerosis, focal osteolysis with cortical } \\
\text { disruption }\end{array}$ & Actinomyces \\
\hline Patient 18 & Irregular area of bony sclerosis & NA \\
\hline \multicolumn{3}{|l|}{ Shin et al. [18] } \\
\hline Patient 19 & $\begin{array}{l}\text { Alveolar bone resorption with internal scattered residual bone } \\
\text { fragments, widening of LPS, and radiolucent lesion }\end{array}$ & NA \\
\hline \multicolumn{3}{|l|}{ Park et al. [19] } \\
\hline Patient 20 & III-defined lytic lesion & $\begin{array}{c}\text { Necrotic bone }+ \text { acute and chronic non- specific inflammation } \\
+ \text { granulation formation }\end{array}$ \\
\hline Patient 21 & III-defined lytic lesion & Necrotic bone \\
\hline Patient 22 & $\begin{array}{c}\text { III-defined lytic lesion, mixed radiolucent and radiopaque } \\
\text { lesions }\end{array}$ & NONE \\
\hline
\end{tabular}

Manfredi et al.[20]

Patient 23 
Table 3 Radiographic and Histologic Features of BRONJ Lesions in Patients with RA (Continued)

\begin{tabular}{|c|c|c|}
\hline Patient 24 & NA & NA \\
\hline \multicolumn{3}{|l|}{ Patient 25} \\
\hline \multicolumn{3}{|l|}{ Patient 26} \\
\hline \multicolumn{3}{|c|}{$\begin{array}{l}\text { Conte-Neto et al. } \\
{[21]}\end{array}$} \\
\hline Patient 27 & Radiolucent lesions and sequestration & $\begin{array}{c}\text { Necrotic lamellar bone }+ \text { chronic and acute inflammatory cells } \\
\qquad+ \text { bacterial colonies }\end{array}$ \\
\hline Patient 28 & Osteosclerosis and osteolysis & NA \\
\hline
\end{tabular}

ID Impossible to determine, CLP chronic lympho-plasmacytic, NA not available, PLS periodontal ligament space, PM premolar

Table 4 Management and Outcomes of BRONJ Lesions in Patients with RA

\begin{tabular}{|c|c|c|}
\hline Authors & Management & Outcomes \\
\hline \multicolumn{3}{|l|}{$\begin{array}{l}\text { Marunick et al. } \\
{[4]}\end{array}$} \\
\hline Patient 1 & ATB + Oral Rinses and sequestrectomy & No healing \\
\hline \multicolumn{3}{|l|}{ Yarom et al. [6] } \\
\hline Patient 2 & $\begin{array}{l}\text { ATB and curettage }+ \text { debridement }+ \\
\text { resection }\end{array}$ & No healing \\
\hline Patient 3 & $\begin{array}{l}\text { ATB and curettage }+ \text { debridement }+ \\
\text { resection }\end{array}$ & Partial healing \\
\hline \multicolumn{3}{|l|}{$\begin{array}{l}\text { Malden \& Pai } \\
{[7]}\end{array}$} \\
\hline Patient 4 & ATB $+C L X+D D$ and debridement & Progressive improvement \\
\hline \multicolumn{3}{|l|}{$\begin{array}{c}\text { Khamaisi et al. } \\
\text { [8] }\end{array}$} \\
\hline Patient 5 & NA & NA \\
\hline \multicolumn{3}{|l|}{ Marx et al. [9] } \\
\hline Patient6 & $C L X+D D^{*}$ & Complete healing \\
\hline Patient7 & $C L X+D D^{*}$ & Complete healing \\
\hline Patient 8 & $C L X+D D^{*}$ & Complete healing \\
\hline \multicolumn{3}{|l|}{ Hamada [10] } \\
\hline Patient 9 & $\mathrm{CT}$ & Partial Improvement \\
\hline \multicolumn{3}{|l|}{ Barrow [11] } \\
\hline Patient 10 & NA & NA \\
\hline \multicolumn{3}{|l|}{$\begin{array}{c}\text { Junquera et al. } \\
{[12]}\end{array}$} \\
\hline Patient $12 a$ & $\mathrm{ATB}+\mathrm{CLX}$ & Complete healing \\
\hline Patient $12 b$ & DD and sequestrectomy & Remission of symptoms \\
\hline \multicolumn{3}{|c|}{$\begin{array}{c}\text { Mehanna et al. } \\
\text { [13] }\end{array}$} \\
\hline Patient 13 & $\mathrm{ATB}+\mathrm{DD}+$ drainage & Complete healing \\
\hline \multicolumn{3}{|l|}{ Favia et al. [14] } \\
\hline Patient $14 a$ & $A T B+C L X+D D$ & Partial Improvement \\
\hline Patient $14 b$ & $A T B+C L X+D D$ & Partial Improvement \\
\hline
\end{tabular}

Kwon et al.

[15]
Patient 15 Sequestrectomy and $\mathrm{CT}$ and resection Sequestrectomy: no healing. CT: complete healing in mx and no healing in Md. and debridement $+\mathrm{DD}$ Resection and debridement: healing after 6 months

Sedghizadeh et

$$
\text { al. [16] }
$$

Patient $16 \quad \mathrm{ATB}+\mathrm{CLX}+\mathrm{DD}+$ sequestrectomy + debridement 
Table 4 Management and Outcomes of BRONJ Lesions in Patients with RA (Continued)

\begin{tabular}{|c|c|c|}
\hline Patient 17 & $\begin{array}{c}\mathrm{ATB}+\mathrm{CLX}+\mathrm{DD} \text { and sequestrectomy }+ \\
\text { debridement }\end{array}$ & No healing \\
\hline Patient 18 & $\mathrm{ATB}+\mathrm{CLX}+\mathrm{DD}$ & No healing \\
\hline \multicolumn{3}{|c|}{ Shin et al. [18] } \\
\hline Patient 19 & $\mathrm{ATB}+\mathrm{DD}+\mathrm{CLX}+$ debridement & Satisfactory healing \\
\hline \multicolumn{3}{|c|}{ Park et al. [19] } \\
\hline Patient 20 & $A T B+D D+C L X+$ curettage & Satisfactory healing \\
\hline Patient 21 & $\mathrm{ATB}+\mathrm{DD}+\mathrm{CLX}+$ curettage & NA \\
\hline Patient 22 & $\mathrm{ATB}+\mathrm{DD}+\mathrm{CLX}$ & Satisfactory healing \\
\hline \multicolumn{3}{|c|}{$\begin{array}{l}\text { Manfredi et al. } \\
{[20]}\end{array}$} \\
\hline Patient 23 & DD & NA \\
\hline Patient 24 & $\mathrm{DD}+\mathrm{ATB}+$ Laser & Partial healing \\
\hline Patient 25 & ATB + Laser & Partial healing \\
\hline Patient 26 & ATB & Partial healing \\
\hline \multicolumn{3}{|c|}{$\begin{array}{l}\text { Conte-Neto et } \\
\text { al. [21] }\end{array}$} \\
\hline Patient 27 & $\begin{array}{c}\mathrm{ATB}+\mathrm{DD}+\mathrm{CLX}+\text { sequestrectomy }+ \\
\text { debridement }\end{array}$ & Complete healing \\
\hline Patient 28 & $\begin{array}{c}\mathrm{ATB}+\mathrm{DD}+\mathrm{CLX}+\text { curettage }+ \\
\text { debridement }\end{array}$ & Complete healing \\
\hline
\end{tabular}

*It was not possible to determine which ATB was prescribed to these patients

ATB antibiotic therapy, $C L X$ chlorhexidine, DD drug discontinuation, $C T$ conservative treatment, NA not available

BRONJ lesions in patients with RA is expected to be quite low, however it should be considered that the proportion of patients with rheumatic disease among all the population sampled in these studies is probably reduced as well.

At the same time, it is reasonable to expect an increased tendency in the number of BRONJ lesions in RA patients considering that there is a lack of knowledge about this disease among rheumatologists in many countries and that BPs are among the most frequent prescribed drugs in rheumatologic practice [28]. This is due to the high efficiency of BPs in the prevention and treatment of osteoporosis, which is a common feature in RA [29].

There is a considerable discussion in the literature whether aging plays a significant role in BRONJ development. Some studies found no statistically significant correlation between aging and BRONJ [30,31]. Therefore, the advanced age of the patients with BRONJ observed in the studies $[6,8,10-12,14-16,18-21]$ may reflect nothing less than the increased BPs prescription to older patients compared with younger ones, since osteoporosis and RA are commonly seen in the elderly $[29,32]$.

On the other hand, other authors include advanced age as a BRONJ co-factor [19,33,34], which could be related to the physiological effects of aging, including inflammatory issues [35], immune dysfunction [36], reduction of the blood flow and the remodeling ability $[37,38]$, and increased oxidative stress [39]. In fact, these features are all implicated with BRONJ pathogenesis and could explain why this disease is not reported in young patients, even with other risk factors associated [40]. Paradoxically, BPs have been prescribed for the treatment of steroid-induced osteonecrosis of the joints in pediatric populations [41].

Controversial aspects have also been discussed regarding gender as a BRONJ co-factor. Some studies found no statistically significant correlation between gender and BRONJ $[33,34]$. Therefore, we observed that the large proportion of female patients from the studies [4,6-11,13-16,18-21] can represent only a coincidence, since women take oral BPs more frequently than males, especially because RA and osteoporosis are more common in women [42].

In spite of that, other authors reported a positive correlation between gender and BRONJ [19]. It has been speculated that estrogen therapy may play a role in this correlation, since hormonal reposition has been associated with an increased risk of BRONJ [43]. The concern is that hormonal replacement therapy is likely to occur in RA, since this disease is often worsened after estrogen delivery [44]. In fact, the association of BPs and estrogen reposition is especially possible in patients with no satisfactory outcomes associated with a single drug therapy or who have very low bone density with multiple risks [45]. Moreover, treatment with estrogen/ bisphosphonate conjugate drugs has also been described [46]. 
It is not surprising that osteoporosis was the most prevalent co-morbidity observed in the studies [4,9-11,14-16,18-21], since this is a common feature in RA patients for several reasons, including: (a) postmenopausal women represent part of the main risk group for RA and are at risk for accentuated bone loss; (b) steroid therapy is often prescribed for the treatment of RA; (c) physical inactivity is characteristic of RA due to disease activity; and (d) bone loss due to inflammatory disease mechanisms, such as elevated levels of systemic cytokines [29].

It has been shown that there is a direct relation between BRONJ occurrence and BPs potency [13,33], which is supported by the high incidence of BRONJ in patients receiving intravenous BPs [47], as well as by faster lesion onset in these patients [24]. This assumption corroborates with the higher incidence of BRONJ in patients using alendronate, as seen in the studies revised here $[4,6-9,11,12,15,16,18-21]$, since it is the most potent drug among the BPs [9].

In contrast, Kos and Luczak [48] found no correlation between the type of BPs and BRONJ incidence, which reinforces the assumption that it can be only a coincidence. In fact, over the last decade, alendronate was among the most used drugs in the USA as first-line therapy for the prevention or treatment of osteoporosis [49], both in non-neoplasic BRONJ patients without RA $[6,9,14,16]$ and in patients with RA [32]. Furthermore, it is reasonable to understand why ibandronate, a potent nitrogen-containing bisphosphonate (N-BPs) [7] that is much less prescribed compared with alendronate, is not associated with large-series cases of BRONJ [23].

It has been discussed that one of the most critical factors for BRONJ is the duration of oral BPs therapy [9,33]. It is believed that there is an increased incidence of oral BRONJ in patients treated with oral BPs for more than 3 years $[5,9]$, which is in agreement with the findings of the studies revised here $[4,6,9,12,15-17,19-21]$. In fact, longerterm use of oral BPs may have a dose-equivalence effect, potentially approximating BPs levels in bone thought to be achieved only through high-dose intravenous delivery [16], and the total dose administered over a long period of time is important for the magnitude of the bone turnover reduction [50].

An interesting observation is that it has been suggested a trend of early-onset lesions due to steroids therapy [9]. However, this tendency was not confirmed in the patients of the studies revised in this paper, since the mean duration of BP therapy in steroid-treated patients was similar to patients that have not been treated with this drug. Furthermore, some authors reported early-onset lesions in patients with RA and no history of steroids [3,19].

The literature indicates a strong association of BRONJ with dental surgical procedures in all groups of patients
$[3,5,9]$. Although we also observed this tendency in the large number of lesions triggered by teeth extractions and dental implants in the studies that were retrieved $[4,5,7-9,12,14,17-20]$, it is relevant to state that spontaneous occurrence of BRONJ lesions was observed in a significant proportion of individuals in several studies $[9,10,12,13,15,19-21]$.

Most of the lesions in the studies were diagnosed in lower jaw at stage II or III [4,6-21] with the most common clinical findings being bone exposure, pain, edema, and purulent discharge. In fact, it also represents the same clinical aspects found in patients with no RA $[6,9,14,16]$. This evidence brings to light the lack of knowledge and attention about early clinical features that include nonspecific signs and symptoms in the oral cavity, including no clinical evidence of bone exposure. The concern is that lesions can progress rapidly, and, in advanced stages, paresthesia, fistula formation, and pathologic fracture can also occur, even in RA patients [6].

The typical imaging finding in all groups of patients with BRONJ is the association of osteolysis and sclerosis aspects. Within this context, when it is considered that bone sclerosis is often detected in the initial stages of BRONJ [51], this sign can also be maintained in advanced stages; indeed, we observed in the studies that bone sclerosis was reported in six patients, all classified in advanced stages $[7,12,17,19,21]$. Therefore, a careful dental examination could allow an early diagnosis and intervention and assist the patients in responding more promptly to stagespecific treatment regimens for BRONJ.

Regarding the management and outcomes of BRONJ lesions in patients with RA, there is no widely accepted treatment protocol to BRONJ. Some authors believe that surgical procedures are not effective in patients with BRONJ and have led to further bone exposure, worsening of symptoms, and a greater risk of pathologic fracture, indicating conservative approaches as the best choice, including antibiotics, oral rinses with chlorhexidine, and 'drug holidays' [47]. In contrast, other authors believe that surgical procedures may achieve better outcomes in non-neoplasic patients [14].

In the papers that we revised, the lesions were treated either by conservative therapy (48\%) or its association with surgical procedures (52\%). Overall, this literature review showed that most of the lesions were treated with conservative approach $[9,10,12,14,17,19,20]$ and were associated with the most positive outcomes including the complete healing of the lesions (33.3\%) and no healing in only one patient (8.33\%) [17] (Table 4). However, in other studies $[4,6,7,12,13,15-19,21]$ the association of conservative and surgical therapy showed more diverse outcomes, with complete healing in only three lesions $(25 \%)[13,21]$.

In fact, the management of BRONJ lesions is a great challenge, which reinforces the necessity of an adequate 
oral care through routine dental examinations, education and motivation of the patients to adopt preventive measures in order to maintain a good oral hygiene and [52].

\section{Conclusion}

The main characteristics of BRONJ patients with RA are generally similar to those with no RA. This critical review highlights a serious concern regarding the delayed diagnosis of BRONJ lesions, since most of these patients were diagnosed in stage II/III. It is clear that the rheumatologist needs to be aware of the potential risk of their patients developing BRONJ and must work together with the dentist to prevent and detect the lesions as soon as possible.

\section{Authors' contributions}

NCN analyzed the records, reviewed all patients' data. ASB drafted the manuscript and helped in writing the text. RACM and EMJ drafted the manuscript and reviewed it critically. All authors read and approved the final manuscript.

\section{Authors' information}

NCN is a PhD student from Implantology program at Araraquara School of Dentistry and ASB is a PhD student from Periodontology program at Araraquara School of Dentistry. EMJ and RACM are professors and chairmen of the Department of Diagnosis and Surgery, Division of Periodontology at Araraquara School of Dentistry.

\section{Competing interests}

The authors declare that they have no competing interests.

Received: 18 October 2011 Accepted: 1 March 2012

Published: 1 March 2012

\section{References}

1. Rogers MJ, Gordon S, Benford HL, Coxon FP, Luckman SP, Monkkonen J, et al: Cellular and molecular mechanisms of action of bisphosphonates. Cancer 2000, 88:2961-2974.

2. Breuil V, Euller-Ziegler L: Bisphosphonate therapy in rheumatoid arthritis Joint Bone Spine 2006, 73:349-354

3. Ruggiero SL, Mehrotra B, Rosenberg TJ, Engroff SL: Osteonecrosis of the jaws associated with the use of bisphosphonates: a review of 63 cases. J Oral Maxillofac Surg 2004, 62:527-534.

4. Marunick M, Miller R, Gordon S: Adverse oral sequelae to bisphosphonate administration. J Mich Dent Assoc 2005, 87:44-49.

5. Ruggiero SL, Dodson TB, Assael LA, Landesberg R, Marx RE, Mehrotra B: American association of oral and maxillofacial surgeons position paper on bisphosphonate-related osteonecrosis of the jaw - 2009 update. J Oral Maxillofac Surg 2009, 67:2-12.

6. Yarom N, Yahalom R, Shoshani Y, Hamed W, Regev E, Elad S: Osteonecrosis of the jaw induced by orally administered bisphosphonates: incidence, clinical features, predisposing factors and treatment outcome. Osteoporos Int 2007, 18:1363-1370.

7. Malden NJ, Pai AY: Oral bisphosphonate associated osteonecrosis of the jaws: three case reports. Br Dent J 2007, 203:93-97.

8. Khamaisi M, Regev E, Yarom N, Avni B, Leitersdorf E, Raz I, et al: Possible association between diabetes and bisphosphonate-related jaw osteonecrosis. J Clin Endocrinol Metab 2007, 92:1172-1175.

9. Marx RE, Cillo JE, Ulloa JJ: Oral bisphosphonates induced osteonecrosis: risk factors, prediction of risk using serum CTX testing, prevention, and treatment. J Oral Maxillofac Surg 2007, 65:2397-2410.

10. Hamada S: Osteonecrosis of jaw associated with oral application of bisphosphonates. J Oral Maxillofac Surg 2007, 65:43.

11. Barrow SY: Is your knowledge up-to-date? Int J Dent Hyg 2010, 8:319-323.
12. Junquera L, Gallego L, Cuesta P, Pelaz A, de Vicente JC: Clinical experiences with bisphosphonate-associated osteonecrosis of the jaws: analysis of 21 cases. Am J Otolaryngol 2009, 30:390-395.

13. Mehanna P, Goddard R: Bisphosphonate associated osteonecrosis: an unusual case. Aust Dent J 2010, 55:311-313.

14. Favia G, Pilolli GP, Maiorano E: Osteonecrosis of the jaw correlated to bisphosphonate therapy in non-oncologic patients: clinicopathological features of 24 patients. J Rheumatol 2009, 36:2780-2787.

15. Kwon YD, Kim YR, Choi BJ, Lee DW, Kim DY: Oral bisphosphonate-related osteonecrosis of the jaws: favorable outcome after bisphosphonate holiday. Quintessence Int 2009, 40:277-278.

16. Sedghizadeh PP, Stanley K, Caligiuri M, Hofkes S, Lowry B, Shuler CF: Oral bisphosphonate use and the prevalence of osteonecrosis of the jaw: an institutional inquiry. J Am Dent Assoc 2009, 140:61-66.

17. Lo JC, O'Ryan FS, Gordon NP, Yang J, Hui RL, Martin D, et al: Prevalence of osteonecrosis of the jaw in patients with oral bisphosphonate exposure. J Oral Maxillofac Surg 2010, 68:243-253.

18. Shin EY, Kwon YH, Herr Y, Shin SI, Chung JH: Implant failure associated with oral bisphosphonate-related osteonecrosis of the jaw. J Periodontal Implant Sci 2010, 40:90-95.

19. Park W, Kim NK, Kim MY, Rhee YM, Kim HJ: Osteonecrosis of the jaw induced by oral administration of bisphosphonates in Asian population: five cases. Osteoporos Int 2010, 21:527-533.

20. Manfredi M, Merigo E, Guidotti R, Meleti M, Vescovi P: Bisphosphonaterelated osteonecrosis of the jaws: a case series of 25 patients affected by osteoporosis. Int J Oral Maxillofac Surg 2011, 40:277-284.

21. Conte-Neto N, Bastos AS, Chierici-Marcantonio RA, Marcantonio E Jr: Oral bisphosphonate-related osteonecrosis of the jaws in rheumatoid arthritis patients: a critical discussion and two case reports. Head Face Med 2011, 27:1-7.

22. Hess LM, Jeter JM, Benham-Hutchins M, Alberts DS: Factors associated with osteonecrosis of the jaw among bisphosphonate users. Am J Med 2008, 121:475-483.e3.

23. Filleul O, Crompot E, Saussez S: Bisphosphonate-induced osteonecrosis of the jaw: a review of 2,400 patient cases. J Cancer Res Clin Oncol 2010, 136:1117-1124

24. Mavrokokki T, Cheng A, Stein B, Goss A: Nature and frequency of bisphosphonate-associated osteonecrosis of the jaws in Australia. J Oral Maxillofac Surg 2007, 65:415-423.

25. Felsenberg D, Hoffmeister B, Amling M, Mundlos S, Seibel MJ, Fratzl P: Kiefernekrosen nach hoch dosierter bisphosphonattherapie. Deutsches Arzteblatt 2006, 103:A3078-A3080

26. Khosla S, Burr D, Cauley J, Dempster DW, Ebeling PR, Felsenberg D, et al Bisphosphonate-associated osteonecrosis of the jaw: report of a task force of the american society for bone and mineral research. J Bone Miner Res 2007, 22:1479-1491.

27. Sambrook P, Olver I, Goss A: Bisphosphonates and osteonecrosis of the jaw. Aust Fam Physician 2006, 35:801-803.

28. Yip RML: Bisphosphonates and osteonecrosis of the jaw. Hong Kong Bull Rheum Dis 2008, 8:19-25.

29. Joffe I, Epstein S: Osteoporosis associated with rheumatoid arthritis: pathogenesis and management. Semin Arthritis Rheum 1991, 20:256-272.

30. Baqain ZH, Sawair FA, Tamimi Z, Bsoul N, Al Edwan G, Almasad JK, et al: Osteonecrosis of jaws related to intravenous bisphosphonates: the experience of a Jordanian teaching hospital. Ann R Coll Surg Engl 2010, 92:489-494.

31. Vahtsevanos K, Kyrgidis A, Verrou E, Katodritou E, Triaridis S, Andreadis CG, et al: Longitudinal cohort study of risk factors in cancer patients of bisphosphonate-related osteonecrosis of the jaw. J Clin Oncol 2009, 27:5356-5362.

32. Lems WF, Lodder MC, Lips P, Bijlsma JW, Geusens P, Schrameijer N, et al: Positive effect of alendronate on bone mineral density and markers of bone turnover in patients with rheumatoid arthritis on chronic treatment with low-dose prednisone: a randomized, double-blind, placebo-controlled trial. Osteoporos Int 2006, 17:716-723.

33. Bamias A, Kastritis E, Bamia C, Moulopoulos LA, Melakopoulos I, Bozas G, et al: Osteonecrosis of the jaw in cancer after treatment with bisphosphonates: incidence and risk factors. J Clin Oncol 2005, 23:8580-8587. 
34. Hoff AO, Toth BB, Altundag K, Guarneri V, Adamus A, Nooka AK, et al: Osteonecrosis of the jaw in patients receiving intravenous bisphosphonate therapy. J Clin Oncol 2006, 24:8528.

35. Schiffrin EJ, Morley JE, Donnet-Hughes A, Guigoz Y: The inflammatory status of the elderly: the intestinal contribution. Mutat Res 2010 690:50-56.

36. Johnson TE: Recent results: biomarkers of aging. Exp Gerontol 2010, 41:1243-1246.

37. Misawa Y, Kageyama T, Moriyama K, Kurihara S, Yagasaki H, Deguchi T, et al: Effect of age on alveolar bone turnover adjacent to maxillary molar roots in male rats: a histomorphometric study. Arch Oral Biol 2007, 52:44-50.

38. Semba I, Funakoshi K, Kitano M: Histomorphometric analysis of age changes in the human inferior alveolar artery. Arch Oral Biol 2001, 46:13-21.

39. Kulikov VY, Fridman YM, Fomin AN: Role of oxidative stress in mechanisms of premature aging in shift labor workers. Alaska Med 2007, 49:81-84.

40. Maines E, Monti E, Doro F, Morandi G, Cavarzere P, Antoniazzi F: Children and adolescents treated with neridronate for osteogenesis imperfecta show no evidence of any osteonecrosis of the jaw. J Bone Miner Metab 2011.

41. Chahine C, Cheung MS, Head TW, Schwartz S, Glorieux FH, Rauch F: Tooth extraction socket healing in pediatric patients treated with intravenous pamidronate. J Pediatr 2008, 153:719-720.

42. Markenson JA: Worldwide trends in the socioeconomic impact and longterm prognosis of rheumatoid arthritis. Semin Arthritis Rheum 1991, 21:4-12.

43. American Dental Association Council on Scientific Affairs: Dental management of patients receiving oral bisphosphonate therapy: expert panel recommendations. J Am Dent Assoc 2006, 137:1144-1150.

44. Barrett JH, Brennan P, Fiddler M, Silman A: Breast-feeding and postpartum relapse in women with rheumatoid and inflammatory arthritis. Arthritis Rheum 2000, 43:1010-1015.

45. Tseng LN, Sheu WH, Ho ES, Lan HH, Hu CC, Kao CH: Effects of alendronate combined with hormone replacement therapy on osteoporotic postmenopausal Chinese women. Metabolism 2006, 55:741-747.

46. Morioka M, Kamizono A, Takikawa H, Mori A, Ueno H, Kadowaki S, et al: Design, synthesis, and biological evaluation of novel estradiolbisphosphonate conjugates as bone-specific estrogens. Bioorg Med Chem 2010, 18:1143-1148.

47. Marx RE, Sawatari Y, Fortin M, Broumand V: Bisphosphonate-induced exposed bone (osteonecrosis/osteopetrosis) of the jaws: risk factors, recognition, prevention, and treatment. J Oral Maxillofac Surg 2005, 63:1567-1575

48. Kos M, Luczak K: Bisphosphonates promote jaw osteonecrosis through facilitating bacterial colonization. Biosci Hypotheses 2009, 2:34-36.

49. Siris ES, Pasquale MK, Wang Y, Watts NB: Estimating bisphosphonate use and fracture reduction among U.S. women age 45 and older, 2001-2008. J Bone Miner Res 2011, 23:3-11.

50. Chapurlat RD, Delmas PD: Drug insight: bisphosphonates for postmenopausal osteoporosis. Nat Clin Pract Endocrinol Metab 2006, 2:211-219.

51. Arce K, Assael LA, Weissman JL, Markiewicz MR: Imaging findings in bisphosphonate-related osteonecrosis of jaws. J Oral Maxillofac Surg 2009, 67:75-84.

52. Yoneda T, Hagino H, Sugimoto $T$, Ohta $H$, Takahashi $S$, Soen $S$, et al: Bisphosphonate-related osteonecrosis of the jaw: position paper from the allied task force committee of Japanese society for bone and mineral research, Japan osteoporosis society, Japanese society of periodontology, Japanese society for oral and maxillofacial radiology, and Japanese society of oral and maxillofacial surgeons. J Bone Miner Metab 2010, 28:365-383.

doi:10.1186/1746-160X-8-5

Cite this article as: Conte-Neto et al:: Epidemiological aspects of rheumatoid arthritis patients affected by oral bisphosphonate-related osteonecrosis of the jaws. Head \& Face Medicine 2012 8:5.

\section{Submit your next manuscript to BioMed Central and take full advantage of:}

- Convenient online submission

- Thorough peer review

- No space constraints or color figure charges

- Immediate publication on acceptance

- Inclusion in PubMed, CAS, Scopus and Google Scholar

- Research which is freely available for redistribution 